\title{
A Case of Aortic Dissection Presenting with Atypical Symptoms and Diagnosed with Transthoracic Echocardiography
}

\author{
Mahdis Solhjoo $\mathbb{D}^{1},{ }^{1}$ Supreeya Swarup, ${ }^{2}$ and Amgad N. Makaryus $\mathbb{D}^{2,3}$ \\ ${ }^{1}$ Departments of Medicine, Nassau University Medical Center, East Meadow, NY, USA \\ ${ }^{2}$ Department of Cardiology, Nassau University Medical Center, East Meadow, NY, USA \\ ${ }^{3}$ Zucker School of Medicine at Hofstra/Northwell Health, Hempstead, NY, USA \\ Correspondence should be addressed to Mahdis Solhjoo; msolhjoo@numc.edu
}

Received 11 June 2019; Revised 9 August 2019; Accepted 17 September 2019; Published 11 November 2019

Academic Editor: Vincent Low

Copyright @ 2019 Mahdis Solhjoo et al. This is an open access article distributed under the Creative Commons Attribution License, which permits unrestricted use, distribution, and reproduction in any medium, provided the original work is properly cited.

\begin{abstract}
We present a case of an extensive aortic dissection (AD) identified in a woman with atypical symptoms. Transthoracic echocardiography (TTE) allowed the identification of an intimal flap in multiple locations and resulted in rapid diagnosis and treatment. In most cases, CT angiography is the imaging modality of choice for diagnosis of AD. TTE is rapid and accurate and can be used in kidney failure. Our case highlights the important role of bedside echocardiography in the diagnosis of AD, especially in the patient with a typical symptoms in whom this diagnosis of $\mathrm{AD}$ may not be entertained and actually missed leading to negative and possibly deadly consequences.
\end{abstract}

\section{Introduction}

The diagnosis of aortic dissection $(\mathrm{AD})$ can be challenging given an extensive range of symptoms at presentation. The mortality rate for untreated patients with $\mathrm{AD}$ after symptoms start is about $1 \%$ per hour. As a result, early diagnosis is required for proceeding with the most appropriate medical or surgical treatment options [1]. In one study, patients with $\mathrm{AD}$ had been misdiagnosed in $16 \%$ of cases presenting to the ER and $\mathrm{AD}$ was not even included in the initial differential diagnoses [2].

One of the fastest and most cost-effective diagnostic methods for $\mathrm{AD}$ is the bedside echocardiogram. We present a case of $\mathrm{AD}$ and highlight the important role of bedside echocardiography in the diagnosis, especially in the patient with atypical symptoms in whom this diagnosis of AD may not be entertained and actually missed leading to negative and possibly deadly consequences.

\section{Case Summary}

A 48-year-old woman presented to the emergency department (ED) with complaints of dizziness, generalized weakness, nausea and diarrhea. The patient assumed her blood pressure was elevated, however, despite oral medications, her symptoms persisted prompting her presentation to the ED. She denied any chest pain, back pain, headache and changes in the vision. She stated that she felt weak on her left side and was unable to move her left lower extremity. The patient's medical history consisted of hypertension, hyperparathyroidism and stage 3 chronic kidney disease. Her home medications for hypertension included Losartan, Amlodipine, Hydralazine and, Carvedilol.

In the $\mathrm{ED}$, the initial vital signs were blood pressure of $125 / 85 \mathrm{mmHg}$ in the right arm and $119 / 83 \mathrm{mmHg}$ in the left arm, pulse rate $64 / \mathrm{min}$, respiration rate $18 / \mathrm{min}$, temperature $97.4^{\circ} \mathrm{F}$ and oxygen saturation of $99 \%$ on room air. The patient was in no acute distress. The cardiac exam showed a normal S1 and S2 with no murmur and the peripheral exam showed normal bilateral peripheral pulses. The neurologic exam showed cranial nerves 2-12 intact with grossly normal motor strength. Electrocardiogram (EKG) showed sinus rate at $63 \mathrm{bpm}$ with occasional ventricular premature complexes, left ventricular hypertrophy and nonspecific ST-segment, $T$-wave changes (Figure 1). Laboratory findings were as follows: creatine kinase (CK) $139 \mathrm{~s} \mathrm{IU} / \mathrm{L}$, CK-myocardial band $2.8 \mathrm{IU} / \mathrm{L}$, troponin I $0.34 \mathrm{ng} / \mathrm{mL}$, white blood cell $15480 / \mu \mathrm{L}$, hemoglobin $14.6 \mathrm{~g} / \mathrm{dL}$, creatinine $2.9 \mathrm{mg} / \mathrm{dl}$ and eGFR $17 \mathrm{ml} / \mathrm{min} / 1.73 \mathrm{~m}^{2}$. 


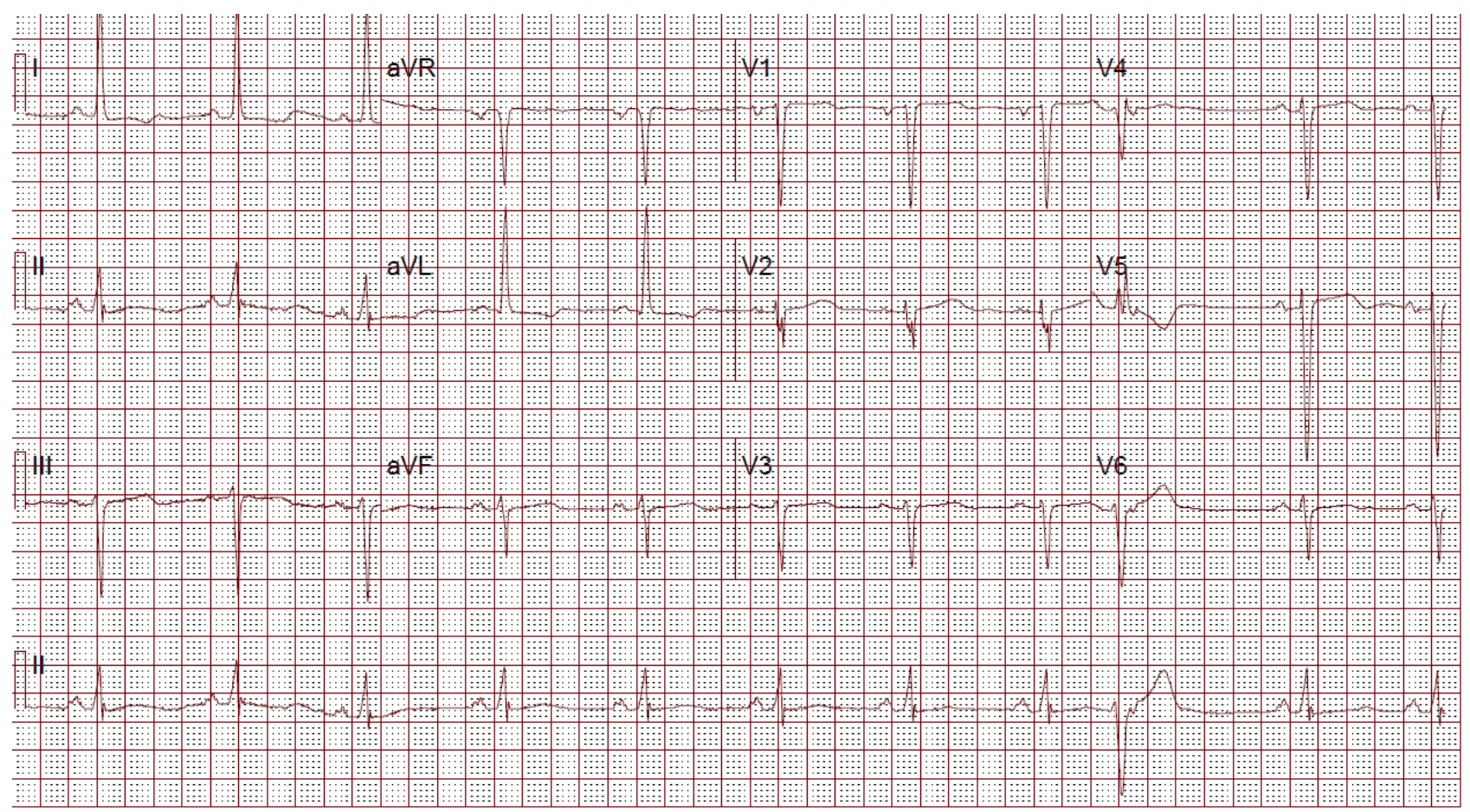

FIGURE 1: EKG showing occasional ventricular premature complexes, left ventricular hypertrophy, with nonspecific ST-segment, $T$-wave changes.

The chest X-ray (CXR) showed a widened mediastinum, enlarged cardiomediastinal silhouette, and longitudinal retrocardiac opacity which was noted by the radiologist to possibly reflect a thoracic aortic aneurysm (Figure 2). Because the patient had elevated creatinine, computed tomography (CT) of thorax without contrast was performed. The CT showed aneurysmal dilatation of the ascending thoracic aorta, measuring up to $4.5 \mathrm{~cm}$ in the axial image (Figure 3 ). From the data above (aortic dissection detection risk score of 1), and given the fact that the Troponin I levels were uptrending, (1.340 ng/ $\mathrm{mL}-1.430 \mathrm{ng} / \mathrm{mL}$ ), evaluation for dissection was undertaken initially utilizing a bedside transthoracic echocardiogram (TTE) which identified an ascending aortic/aortic root aneurysm with a dissection flap (Figures 4-9). Elevating troponin with ascending aortic aneurysm and flap seen on TTE was consistent with type A aortic dissection. The patient was sent for urgent cardiothoracic surgery undergoing transesophageal echocardiography intraoperatively to fully elucidate the dissection extent and underwent a composite graft replacement of the aortic valve, aortic root, and ascending aorta, with re-implantation of the coronary arteries into the graft (Bentall procedure). The patient did well post-surgery without complication.

\section{Discussion}

Chest pain is one of the most common symptoms in dissection and its absence makes the diagnosis difficult for the clinician. One study found that about $71 \%$ of patients with type A dissections presented with anterior chest pain while $6 \%$ did not have any pain [3]. The most common initial diagnosis in patients with $\mathrm{AD}$ are acute coronary syndrome, cerebrovascular accidents, and gastrointestinal and pulmonary diseases. Absence of chest pain, presentation of neurologic deficits, syncope, vascular insufficiency and gastrointestinal (GI) symptoms are some of the symptoms leading to misdiagnosis of $\mathrm{AD}$ [3-5].

Women are also at increased risk of $\mathrm{AD}$ misdiagnosis since $\mathrm{AD}$ is less common in women, usually presents in older women, and has more atypical symptoms $[6,7]$. Less than $5 \%$ of patients with $\mathrm{AD}$ present with GI manifestations such as nausea, vomiting, and bloody diarrhea [8]. In one case report, a patient presented with severe diarrhea and was finally diagnosed with $\mathrm{AD}$ [9]. It is therefore important to have a high clinical suspicion of AD in patients with risk factors and atypical symptoms.

In our case, the patient has multiple factors that routinely lead to misdiagnosis. Our case is a young female with GI symptoms and no specific chest pain. Being aware of having hypertension and noting an aortic aneurysm can be helpful to put the $\mathrm{AD}$ in the initial differential diagnoses list. Although the CXR can be used as a screening tool in chest pain, only about $50 \%$ of patients with $\mathrm{AD}$ have a widened mediastinum or abnormal aortic contour. Studies have found CXR sensitivity and specificity for AD of only $67 \%$ and $70 \%$, respectively $[3,10]$. Troponin levels are positive in about $50 \%$ of the patients with $\mathrm{AD}$ [11]. Also, EKG abnormalities can present in AD similar to myocardial infarction patients. Most common EKG findings are the presence of nonspecific ST-segment or $T$-wave changes and rarely ST-segment elevation or new $Q$ waves [12]. Both high troponin levels and EKG changes can 


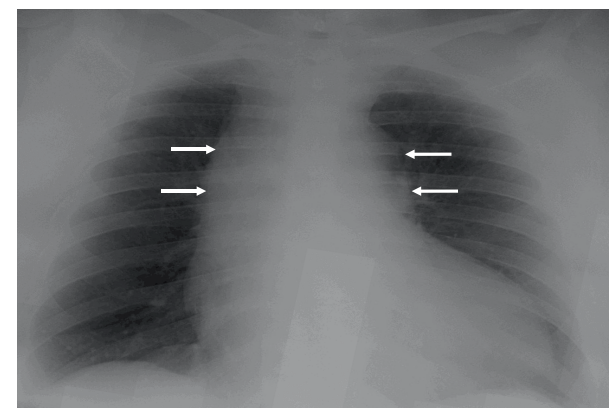

FIGURE 2: CXR showing widened mediastinum (arrows), enlarged cardiomediastinal silhouette and longitudinal retrocardiac opacity.

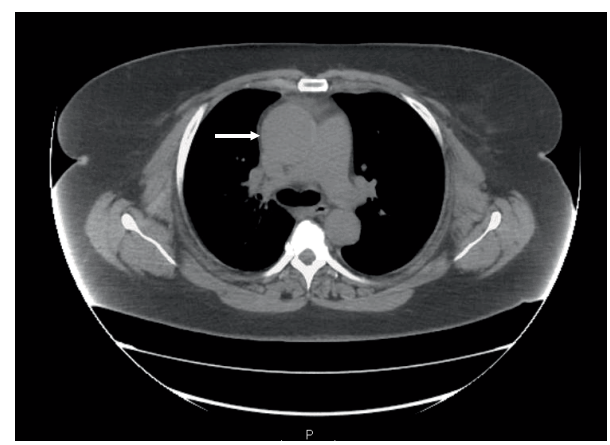

Figure 3: Axial CT image of the thorax without contrast showing aneurysmal dilatation (arrow) of the ascending thoracic aorta.

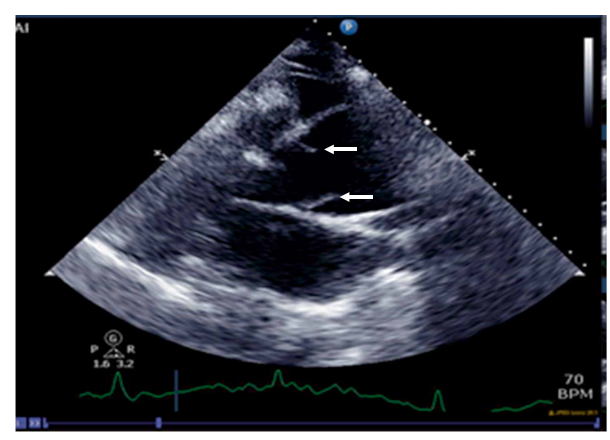

FIgURE 4: Parasternal long axis view showing the dissection flap (arrows) in the ascending aorta.

cause confusion and delay in AD diagnosis that leads to inappropriate treatment with antithrombotics which can cause more complications [13].

Preferred imaging studies in the diagnosis of $\mathrm{AD}$ are echocardiography and CT in the emergency setting and magnetic resonance (MRI) for the stable patients. Although CT and MRI give a better field of view, the role of the echocardiography is very important since it is rapid, portable, and cost-effective in the diagnosis. TTE can assess different aortic segments and visualize an intimal flap in the proximal ascending aorta. In past, the role of TTE was limited in the diagnosis of $\mathrm{AD}$ because its sensitivity was very low in the diagnosis of descending $\mathrm{AD}$ (31-55\%). Currently, with the

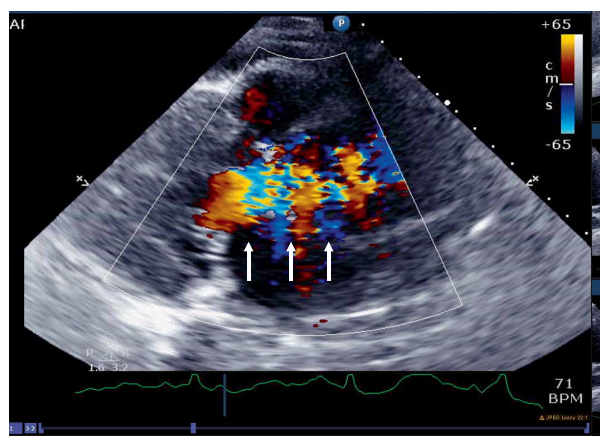

FIgURE 5: Parasternal long axis view showing aortic insufficiency (arrows).

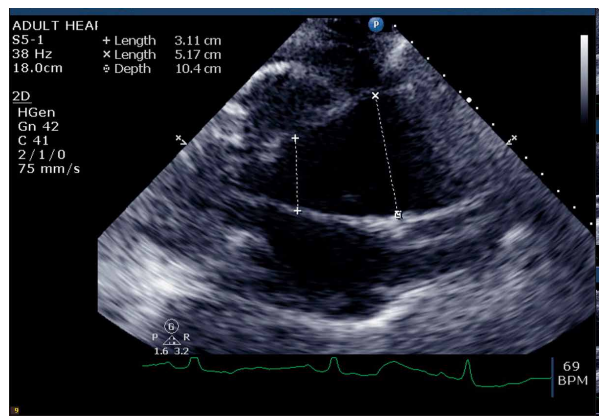

FIgURE 6: Parasternal long axis view showing the ascending aortic aneurysm.

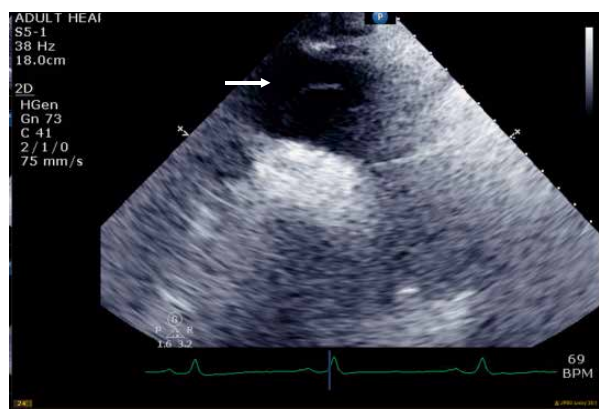

FIgURE 7: Suprasternal notch view showing the dissection flap extending to the aortic arch (arrow).

newest imaging technology, TTE sensitivity and specificity have been improved in the diagnosis of AD [14]. Although trans-esophageal echocardiography (TEE) is the better technique, in many studies TTE has been suggested as the initial imaging in the emergency setting because of its availability and rapidity in the diagnosis of $\mathrm{AD}[11,15,16]$. In our case, AD was diagnosed by TTE. This case emphasizes the role of clinical suspicion of AD. Furthermore, many patients with typical and atypical symptoms for ascending AD can be easily diagnosed with bedside TTE that is both fast and accurate. Recent studies are discussing the importance of TTE in early diagnosis of $\mathrm{AD}$ which can be lifesaving mainly in patients with atypical symptoms. 


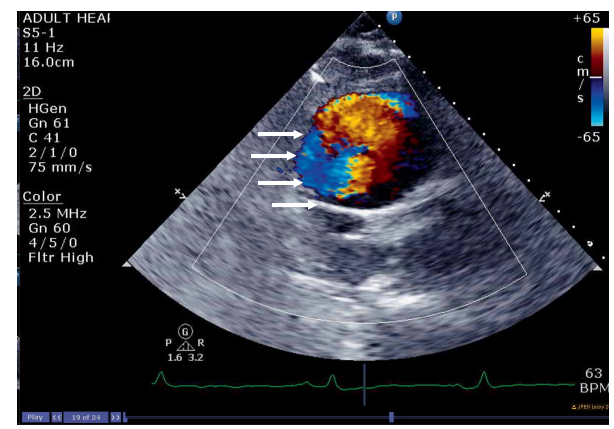

Figure 8: Color Doppler helps in appreciating the true lumen (arrows) from the false lumen.

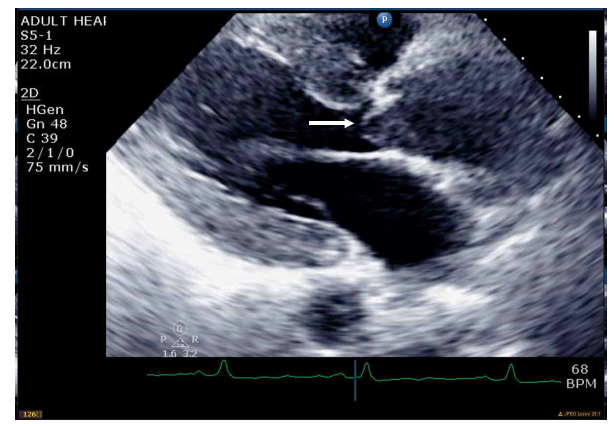

Figure 9: Parasternal long axis view showing dissection flap prolapsing (arrow) into the left ventricular outflow tract causing aortic insufficiency.

\section{Conflicts of Interest}

There are no conflicts of interest regarding the publication of this paper.

\section{References}

[1] M. N. Gionis, G. Kaimasidis, E. Tavlas et al., "Medical management of acute type A aortic dissection in association with early open repair of acute limb ischemia may prevent aortic surgery surgery," American Journal of Case Reports, vol. 14, pp. 52-57, 2013.

[2] M. Kurabayashi, N. Miwa, D. Ueshima et al., "Factors leading to failure to diagnose acute aortic dissection in the emergency room," Journal of Cardiology, vol. 58, no. 3, pp. 287-293, 2011.

[3] S. M. Alter, B. Eskin, and J. R. Allegra, "Diagnosis of aortic dissection in emergency department patients is rare," Western Journal of Emergency Medicine, vol. 16, no. 5, pp. 629-631, 2015.

[4] K. Hirata, M. Wake, T. Takahashi et al., "Clinical predictors for delayed or inappropriate initial diagnosis of type A acute aortic dissection in the emergency room," PLoS One, vol. 10, no. 11, p. e0141929, 2015.

[5] S. Y. Hwang, E. H. Park, E. S. Shin, and M. H. Jeong, "Comparison of factors associated with atypical symptoms in younger and older patients with acute coronary syndromes," Journal of Korean Medical Science, vol. 24, no. 5, pp. 789-794, 2009.

[6] W. D. Clouse, J. W. Hallett, H. V. Schaff et al., "Acute aortic dissection: population-based incidence compared with degenerative aortic aneurysm rupture," Mayo Clinic Proceedings, vol. 79, no. 2, pp. 176-180, 2004.

[7] J. L. Januzzi, E. M. Isselbacher, R. Fattori et al., "Characterizing the young patient with aortic dissection: results from the international registry of aortic dissection (IRAD)," Journal of the American College of Cardiology, vol. 43, no. 4, pp. 665-669, 2004.

[8] A. L. Knaut and J. C. Cleveland, "Aortic emergencies," Emergency Medicine Clinics of North America, vol. 21, no. 4, pp. 817-845, 2003.

[9] R. C. Swazo and B. B. Ainapurapu, "Deadly diarrhea: the clever disguise of aortic dissection," The American Journal of Medicine, vol. 130, no. 2, pp. e61-e62, 2017.

[10] R. Erbel, V. Aboyans, E. Bossone et al., “The task force for the diagnosis and treatment of aortic diseases of the european society of cardiology (ESC). 2014 ESC Guidelines on the diagnosis and treatment of aortic diseases: document covering acute and chronic aortic diseases of the thoracic and abdominal aorta of the adult," European Journal of Heart Failure, vol. 35, no. 41, pp. 2873-2926, 2014.

[11] J. Gawinecka, F. Schönrath, and A. von Eckardstein, "Acute aortic dissection: pathogenesis, risk factors and diagnosis," Swiss Medical Weekly, vol. 25, no. 147, p. w14489, 2017.

[12] P. G. Hagan, C. A. Nienaber, E. M. Isselbacher et al., "The international registry of acute aortic dissection (IRAD)," JAMA, vol. 283, no. 7, pp. 897-903, 2000.

[13] G. J. Koullias, P. Ravichandran, D. P. Korkolis, D. L. Rimm, and J. A. Elefteriades, "Increased tissue microarray matrix metalloproteinase expression favors proteolysis in thoracic aortic aneurysms and dissections," The Annals of Thoracic Surgery, vol. 78, no. 6, pp. 2106-2110, 2004.

[14] A. Evangelista, F. Flachskampf, R. Erbel et al., "Echocardiography in aortic diseases: EAE recommendations for clinical practice," European Journal of Echocardiography, vol. 11, no. 8, pp. 645-658, 2010.

[15] A. Evangelista, F. A. Flachskampf, R. Erbel et al., "Echocardiography in aortic diseases: EAE recommendations for clinical practice," European Journal of Echocardiography, vol. 11, no. 8, pp. 645-658, 2010.

[16] P. Nazerian, C. Mueller, S. Vanni et al., "Integration of transthoracic focused cardiac ultrasound in the diagnostic algorithm for suspected acute aortic syndromes," European Heart Journal, vol. 40, no. 24, pp. 1952-1960, 2019. 


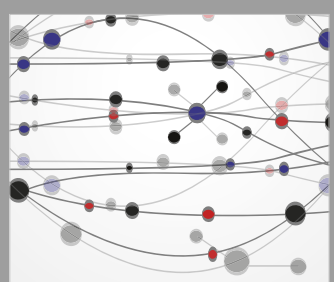

The Scientific World Journal
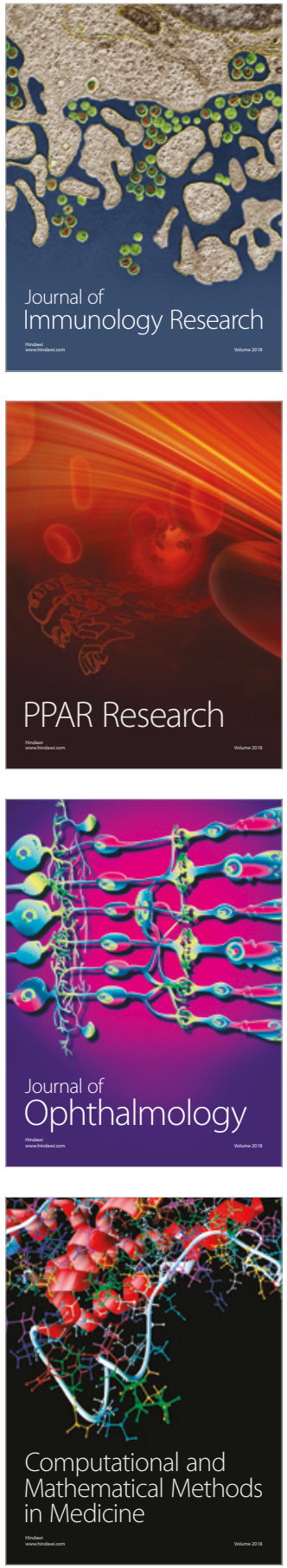

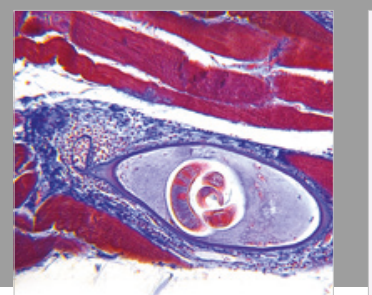

Gastroenterology Research and Practice

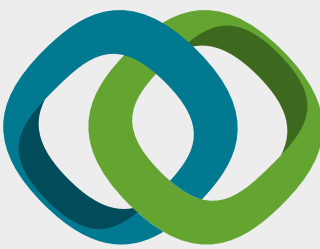

\section{Hindawi}

Submit your manuscripts at

www.hindawi.com
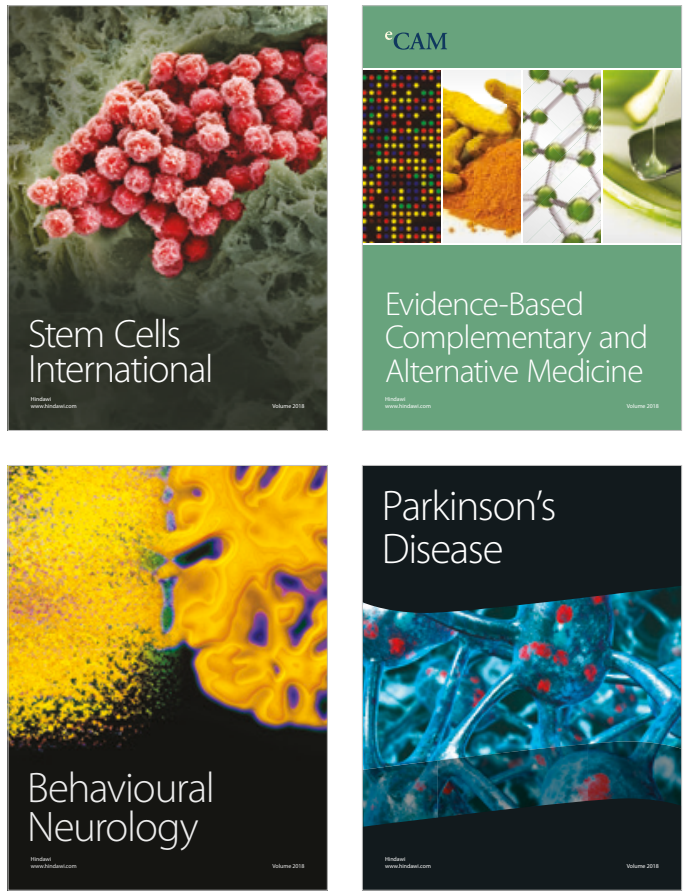

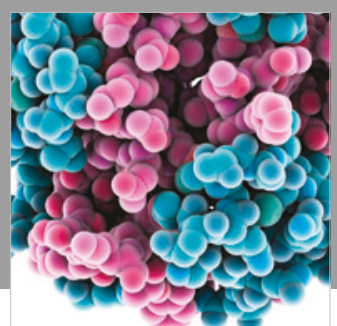

ournal of

Diabetes Research

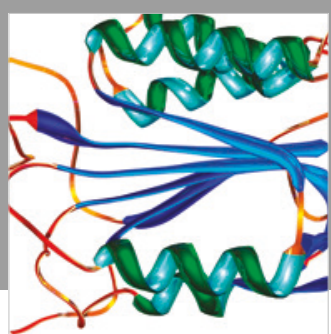

Disease Markers
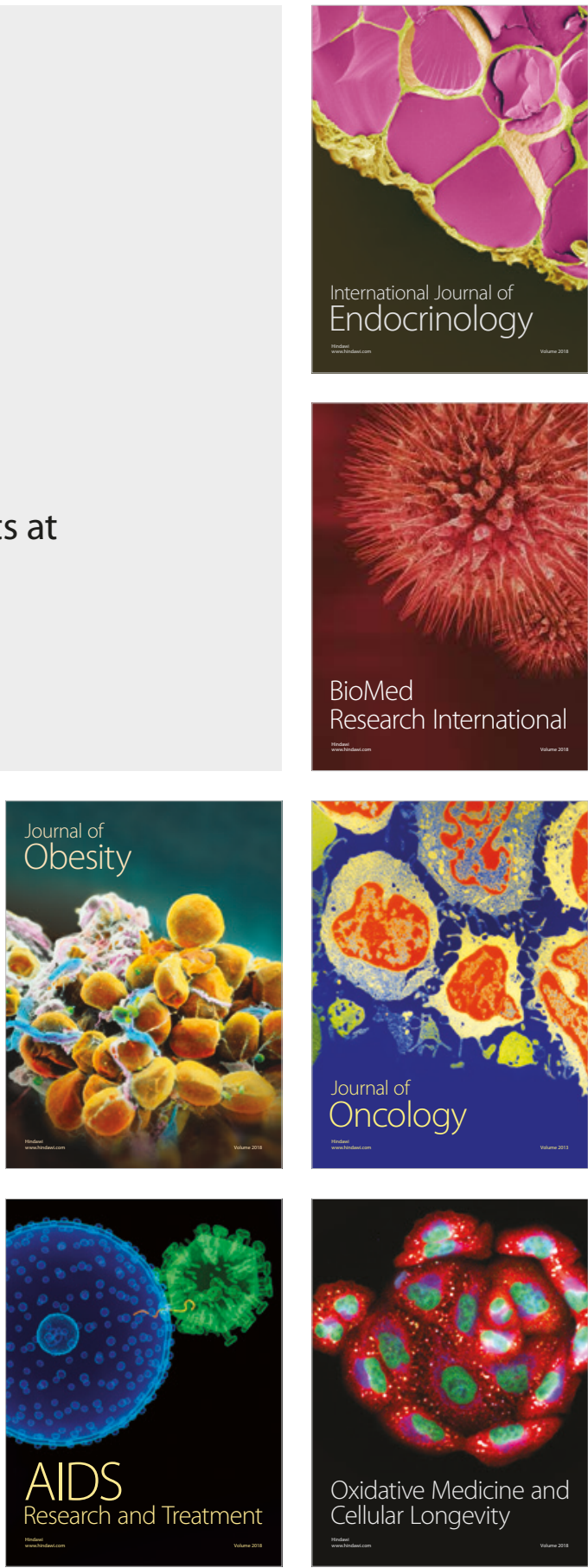